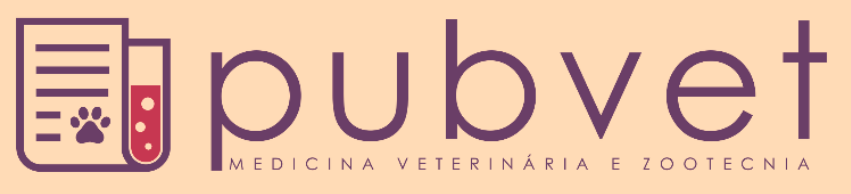

https://doi.org/10.31533/pubvet.v12n12a223.1-8

\title{
Pythium insidiosum em equino: Relato de caso
}

\author{
Débora Zaro ${ }^{1 *}$, Cristine Bitencourt Redivo ${ }^{2}{ }^{\bullet}$, Bárbara Alibio Moraes $^{3}{ }^{\bullet}$, Flávia \\ Umpierre Bueno $^{4}{ }^{\oplus}$, Carlos Afonso de Castro Beck ${ }^{5}$, André Luiz de Araújo Rocha ${ }^{6}$ \\ ${ }^{I}$ Mestranda da Universidade Federal do Rio Grande do Sul, Programa de Pós-Graduação em Medicina Animal: Equinos. Porto Alegre - RS Brasil \\ ${ }^{2}$ Aluna de Graduação em Medicina Veterinária, Faculdade de Veterinária, Universidade Federal do Rio Grande do Sul. Porto Alegre - RS Brasil. \\ ${ }^{3}$ Médica Veterinária, Mestre pelo Programa de Pós-Graduação em Ciências Veterinárias, Universidade Federal do Rio Grande do Sul. Porto Alegre-RS Brasil \\ ${ }^{4}$ Médica Veterinária e Doutoranda, Programa de Pós-Graduação em Medicina Animal: Equinos, Universidade Federal do Rio Grande do Sul. Porto Alegre-RS Brasil. \\ ${ }^{5}$ Professor da Universidade Federal do Rio Grande do Sul, Departamento de Medicina Animal. Porto Alegre - RS Brasil. \\ ${ }^{6}$ Professor da Universidade Federal do Rio Grande do Sul, Departamento de Medicina Animal. Porto Alegre - RS Brasil. \\ *Autor para correspondência,E-mail: deborazaro@hotmail.com
}

RESUMO. A pitiose é uma afecção granulomatosa crônica que acomete os equinos e outras espécies como cães, bovinos, caprinos, felinos, animais silvestres e seres humanos. Ocorre em regiões de climas tropicais, subtropicais ou temperados e em áreas com acúmulo de água, banhados e lagoas. O Brasil está entre os países tropicais como local endêmico de pitiose equina. O agente etiológico em mamíferos é um oomiceto do Reino Stramenopila, Filo Oomycota, Classe Oomycetes, Ordem Pythiales, Família Pyhtiaceae, Gênero Pythium, Espécie Pythium insidiosum. É um parasita de plantas aquáticas, que através de reprodução assexuada produz zoósporos que podem infectar os animais. Causa grandes prejuízos na equinocultura e o prognóstico da doença depende da extensão das lesões e comprometimento de estruturas como tendões, articulações e tecidos ósseos. É uma doença que provoca um quadro infeccioso na pele e região subcutânea, pode apresentar quadros sistêmicos, pulmonares, gastrointestinais, oculares, entre outros. A enfermidade em equinos caracteriza-se pela formação de granulomas eosinofílicos, com a presença de massas necróticas denominadas de "kunkers". Os "kunkers" histologicamente apresentam-se como concreções eosinofílicas de tamanho variado, forma circular, contornos irregulares, compostas de hifas, colágeno, arteríolas e células inflamatórias. Muitos protocolos para tratamento têm sido utilizados: químicos (antifúngicos), cirúrgicos e de imunoterapia. $\mathrm{O}$ tratamento mais indicado para a cura da pitiose em equinos é a remoção cirúrgica do granuloma combinada com a imunoterapia. Porém, o tratamento é complicado devido a características singulares do agente que difere dos fungos verdadeiros na produção de zoósporos móveis e na composição de sua parede celular. Fungos verdadeiros possuem quitina em sua parede, enquanto o Pythium contém celulose e $\beta$-glucanas, o que dificulta a penetração dos fármacos. Neste trabalho, propõe-se relatar um caso de pitiose diagnosticado em um equino atendido no Hospital de Clínicas Veterinárias (HCV) da UFRGS (Universidade Federal do Rio Grande do Sul). Observou-se um tratamento longo, dispendioso, com complicações e reações adversas no local de aplicação do imunoterápico. Contudo, a terapia foi eficiente na diminuição da lesão, melhora do quadro infeccioso da pele e região subcutânea.

Palavras chave: cavalo, fungo, terapêutica, vacina

\section{Pythium insidiosum in equine: Case report}

ABSTRACT. Pythiosis is a chronic granulomatous condition affecting horses and other species such as dogs, cattle, goats, cats, wild animals and humans. It occurs in regions with tropical, subtropical or temperate climates, and in areas with accumulated water, bathed and lagoons. Brazil is among tropical countries as an endemic site of equine pythose.The 
etiologic agent in mammals is an oomycete of the Kingdom Stramenopila, Phylum Oomycota, Class Oomycetes, Order Pythiales, Family Pythiaceae, Genus Pythium, Species Pythium insidiosum. It is a parasite of aquatic plants, which through asexual reproduction produces zoospores that can infect animals. It causes great damages in the echinoculture and the prognosis of the disease depends on the extension of the lesions and compromise of structures such as tendons, joints and bone tissues. It is a disease that causes an infectious picture in the skin and subcutaneous region, however can present systemic picture, pulmonary, gastrointestinal, ocular, among others. The disease in horses characterized by eosinophilic granuloma formation with presence of necrotic masses called "kunkers". The "kunkers" present histologically as eosinophilic concretions of varied size, circular shape, irregular contours, composed of hyphae, collagen, arterioles and inflammatory cells. Many protocols for treatment have been used: chemical (antifungals), surgical and immunotherapy. The most appropriate treatment for pythiosis in horses is the surgical removal of granuloma combined with immunotherapy. However, the treatment is complicated by the unique characteristics of the agent that differs from the true fungi in the production of motile zoospores and in the composition of their cell wall. True fungi possess chitin in their wall, while Pythium contains cellulose and $\beta$-glucans, which makes it difficult to penetrate the drugs. In this work, it is proposed to report a case of pythiosis diagnosed in an equine attended at the Hospital of Veterinary Clinics (HCV) of UFRGS (Federal University of Rio Grande do Sul). A long and expensive treatment with complications and adverse reactions at the immunotherapeutic site was observed. However, the therapy was efficient in reducing the lesion, improving the infections condition of the skin and subcutaneous region.

Keywords: horse, fungus, therapy, vaccine

\section{Pythium insidiosum en equino: Reporte de un caso}

RESUMEN. La pythiosis es una afección granulomatosa crónica que afecta a los equinos y otras especies como perros, bovinos, caprinos, felinos, animales silvestres y seres humanos. Ocurre en regiones de climas tropicales, subtropicales o templados, y en áreas con acumulación de agua, bañados y lagunas. Brasil está entre los países tropicales como local endémico de la pythiosis equina. El agente etiológico en los mamíferos es un oomiceto del Reino Stramenopila, Filo Oomycota, Clase Oomycetes, Orden Pythiales, Familia Pyhtiaceae, Género Pythium, Especies Pythium insidiosum. Es un parásito de las plantas acuáticas, que a través de la reproducción asexual produce zoosporas que pueden infectar a los animales. Causa grandes pérdidas en la equinocultura y el pronóstico de la enfermedad depende de la extensión de las lesiones y el compromiso de estructuras como tendones, articulaciones y tejidos óseos. Es una enfermedad que provoca un cuadro infeccioso en la piel y región subcutánea, puede presentar cuadros sistémicos, pulmonares, gastrointestinales, oculares, entre otros. La enfermedad en los equinos se caracteriza por la formación de granulomas eosinofílicos, con la presencia de masas necróticas llamadas "kunkers". Los "kunkers" histológicamente se presentan como concreciones eosinofílicas de tamaño variado, forma circular, contornos irregulares, compuestas de hifas, colágeno, arteriolas y células inflamatorias. Se han utilizado muchos protocolos de tratamiento:químicos (antifúngicos), quirúrgicos y de inmunoterapia. El tratamiento más indicado para pythiosis equina es la extirpación quirúrgica del granuloma combinada con la inmunoterapia. Sin embargo, el tratamiento es complicado debido a características singulares del agente que difiere de los hongos verdaderos en la producción de zoosporos móviles y en la composición de su pared celular. Los hongos verdaderos poseen quitina en su pared, mientras que el Pythium contiene celulosa y $\beta$-glucanas, lo que dificulta la penetración de los fármacos. En este trabajo, se propone relatar un caso de pythiosis diagnosticado en un equino atendido en el Hospital de Clínicas Veterinarias (HCV) de la UFRGS (Universidad Federal de Rio Grande do Sul). Se observó un tratamiento largo, costoso, con complicaciones y reacciones adversas en el lugar de aplicación del 
inmunoterápico. Sin embargo, la terapia fue eficaz para reducir la lesión y mejorar el estado de las infecciones de la piel y la región subcutánea.

Palabras clave: caballo, hongo, terapéutica, vacuno

\section{Introdução}

Ficomicose era o termo usado para designar micoses causadas por fungos de hifas grandes, com poucos septos, que incluía o gênero causador da pitiose, até então uma doença incurável com indicação de eutanásia (Santúrio \& Ferreiro 2008).

Equinos e caninos podem apresentar a forma gastrointestinal e cutânea. Bovinos cursam com a doença cutânea, ovinos com quadro de linfangite e lesões cutâneas. Felinos e humanos cursam com apresentação de quadro clínico sistêmico, desenvolvimento de arterite, queratite e celulite periorbital. Nas espécies não domésticas foram relatadas doença pulmonar primária, lesões cutâneas, gastrintestinais e lesão mandibular subcutânea. Foram descritos casos de infecção ocular e cutânea em humanos expostos a fatores de risco como traumatismos oculares, uso de lentes de contato e banhos em água contaminada (Castillo-Jiménez et al. 2013).

Casos típicos caracterizam-se por granulomas cutâneos, ulcerados, com abundante secreção serossanguinolenta e prurido. Nos casos atípicos são observadas lesões subcutâneas caracterizadas por grandes massas tumorais circunscritas, recobertas por pele escura, sem ulcerações e pouca secreção (Leal et al. 2001).

Não existe droga antifúngica eficiente contra o agente, o sucesso do tratamento é influenciado pelo tamanho, duração da lesão, idade e estado nutricional do animal (Tomich et al. 2010; $\underline{\text { Álvarez }}$ et al. 2013). O imunoterápico contra pitiose equina, "PitiumVac", com registro de invenção pertencente ao Laboratório de Pesquisas Micológicas da Universidade Federal de Santa Maria (LAPEMI) e Embrapa, mostrou-se eficiente para pitiose clínica. Mas, estudos mostraram que animais que passaram pela primeira infecção e imunoterapia não desenvolveram resposta imunitária suficiente para evitar reinfecção (Santúrio \& Ferreiro 2008; Álvarez et al. 2013).

Este trabalho tem como objetivo relatar um caso de pitiose equina atendido no $\mathrm{HCV}$ da UFRGS em 2013, bem como, discutir os desafios do tratamento e cura da doença.

\section{Relato de caso}

Um equino, macho, não castrado, pesando 270 $\mathrm{kg}$, sem raça definida e de aproximadamente dez anos de idade, foi conduzido ao HCV da UFRGS em março de 2013. O animal apresentava uma lesão ulcerada com aspecto friável no membro pélvico direito (MPD), na região da quartela (Figura 1).

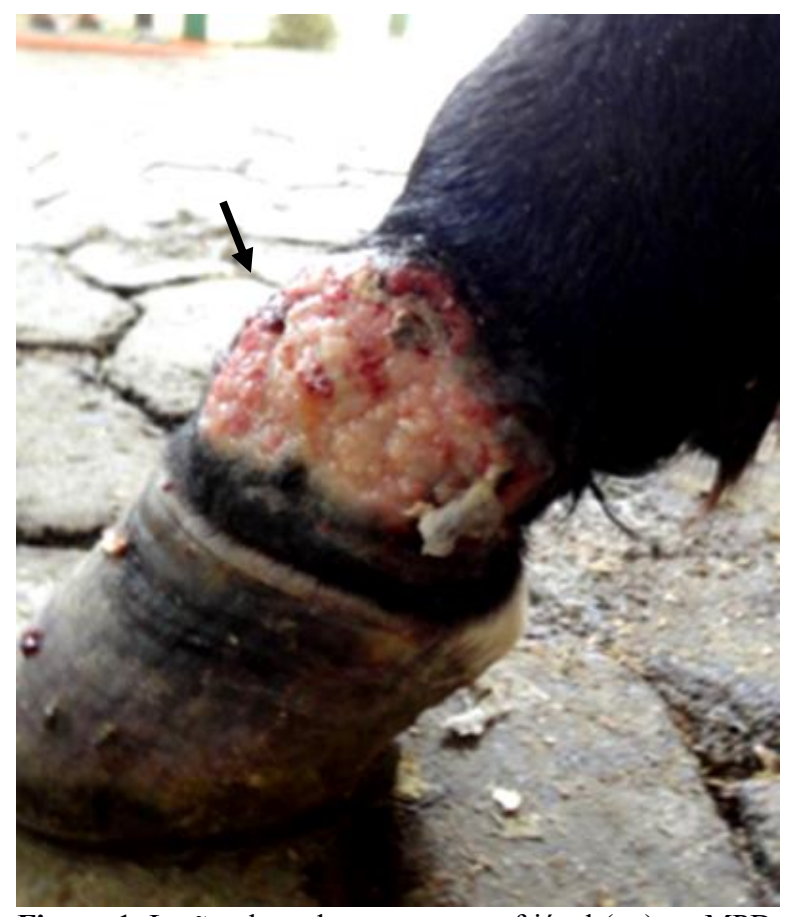

Figura 1. Lesão ulcerada com aspecto friável $(\rightarrow)$ no MPD, região da quartela.

De acordo com o relato do tutor, inicialmente a lesão se assemelhava a uma verruga pequena. Depois começou aumentar de tamanho e evoluiu para uma ferida ulcerada que causava bastante prurido. O local em que o equino permanecia na propriedade era um campo com áreas alagadas e, segundo tutor, o paciente nunca havia apresentado lesões semelhantes.

Antes de encaminhar o animal para atendimento veterinário, o tutor aplicou na ferida um ectoparasiticida (Bactrovet Prata AM, fabricante König A.S) em aerossol de uso externo que possui ação larvicida, bernicida, repelente, cicatrizante, antisséptico, de efeito adstringente e hemostático, cujos princípios ativos são sulfadiazina de prata e cipermetrina. Utilizou uma pomada (Vetaglós, fabricante Vetnil) de uso 
externo com ação anti-infecciosa, epitelizante e cicatrizante que contém agentes antimicrobianos que atuam no combate de micro-organismos que podem estar presentes em infecções dermatológicas, produto que apresenta em sua composição gentamicina, sulfanilamida, sulfadiazina, ureia e vitamina A. Também aplicou por via IM (intramuscular), $20 \mathrm{~mL}$ de uma associação injetável entre antimicrobianos e antiinflamatórios (Megacilin Super Plus, fabricante Agener União Saúde Animal) não hormonal, à base de benzilpenicilina benzatina, benzilpenicilina procaína, benzilpenicilina potássica, estreptomicina e piroxicam, indicada para bovinos, ovinos, caprinos e suínos. Não houve resposta positiva ao tratamento estabelecido pelo tutor e o paciente foi encaminhado ao $\mathrm{HCV}$.

No Hospital de Clínicas Veterinárias da UFRGS, realizou-se a limpeza da ferida com solução fisiológica, coleta de amostras de sangue para hemograma e coleta de material da lesão para exame histopatológico. Não houve alterações significativas nos exames laboratoriais, e o resultado do exame histopatológico foi compatível com diagnóstico de pitiose. A ferida apresentava um aspecto granulomatoso úmido, com exsudato mucoseroso e aparência tumoral. Havia presença de "kunkers" (Figura 2) que são massas brancoamareladas formadas por hifas recobertas por células necróticas, com tamanho que varia de 2 a $10 \mathrm{~mm}$ de diâmetro, possuem um formato irregular, com aspecto arenoso. Os "kunkers" são uma característica da doença e, ao se pressionar a lesão, é possível extraí-los.

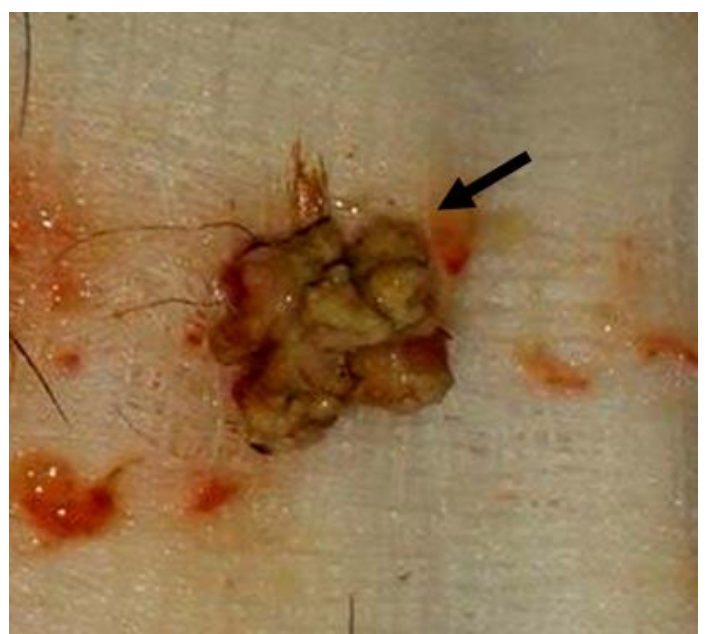

Figura 2. "kunker" retirado da lesão $(\rightarrow)$.

Após a realização da biópsia administrou-se soro antitetânico como conduta profilática e aplicou-se anti-inflamatório não esteroide
(Flunixin, fabricante Chemitec Agro-Veterinária), não narcótico que possui ação analgésica, antitérmica e anti-endotóxica. Foi realizada antibioticoterapia para combater infecções bacterianas secundárias. Diariamente realizou-se higienização da lesão com solução fisiológica, aplicação de pomada à base de calêndula sobre a ferida e, para proteger o local, curativo com gaze, atadura e esparadrapo.

Antes de submeter o paciente ao procedimento cirúrgico para excisão do tecido de granulação exuberante e dos "kunkers", optou-se por debridamento químico local com aplicação de sulfato de cobre sobre a lesão (Figura 3) para auxiliar na diminuição do tamanho da massa tecidual.

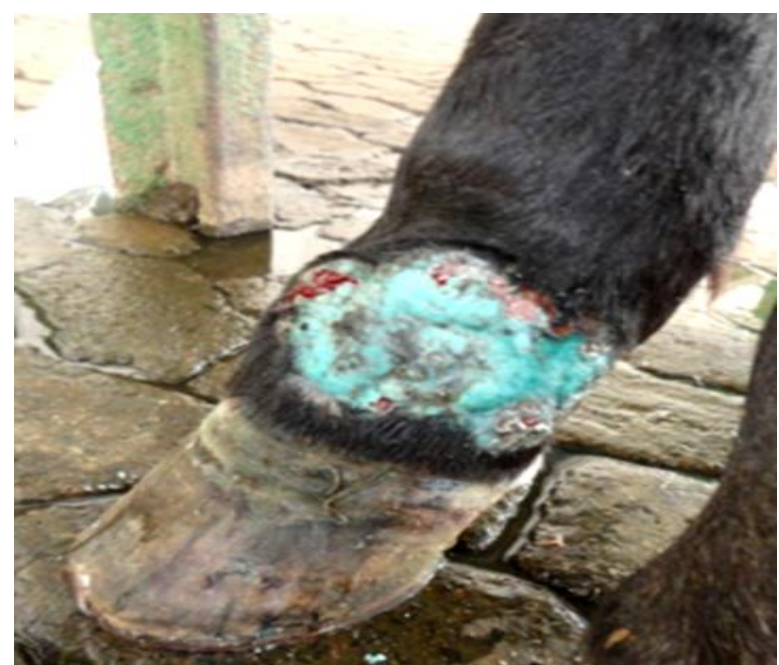

Figura 3. Ferida com sulfato de cobre.

No decorrer do tratamento, o equino apresentou eritropenia, portanto recebeu suplementação líquida via oral (Hemolitan, fabricante Vetnil) indicada para animais em condição nutricional inadequada, e que, segundo fabricante desempenha também atividade na formação de hemácias.

Dez doses do imunoterápico Pitium-Vac por via subcutânea (SC), com intervalo de quinze dias entre uma aplicação e outra foram administradas. Todas as aplicações do imunoterápico causaram formação de abscessos contendo secreção purulenta, edema e dor no local de aplicação. O paciente recebeu iodeto de potássio via oral (VO) por dois meses, no entanto, após esse período a administração do antifúngico foi cancelada, pois o equino apresentou alterações no exame clínico que levaram a suspeita de intoxicação. Porém, as alterações apresentadas pelo paciente como claudicação, ataxia e relutância em mover-se, 
foram causadas pelo desconforto no local de aplicação do imunoterápico (IMT). Devido à relutância em caminhar o paciente não estava se alimentando e ingerindo água adequadamente, apresentou quadro de desidratação e, portanto, recebeu fluidoterapia com ringer lactato. Protetor podal cujo princípio ativo é o alcatrão, também foi utilizado como profilaxia e tratamento de cascos quebradiços.
A sequência detalhada das datas, ordem dos tratamentos e doses realizadas no $\mathrm{HCV}$ se encontra na tabela 1.

A terapia empregada foi eficiente na diminuição da lesão, o processo cicatricial evoluiu e ao final do tratamento a ferida encontrava-se menor e com crescimento de pelos (Figura 4).

Tabela 1. Sequência cronológica do tratamento clínico e cirúrgico realizado no paciente.

\begin{tabular}{ll}
\hline Data & Procedimentos e tratamentos realizados \\
\hline $12 / 03 / 2013$ & Aplicação de Pentabiótico Veterinário Reforçado Pentabiótico Veterinário Reforçado, fabricante Fort \\
& Dodge, 12.000.000 UI/IM $30 \mathrm{~mL}$. \\
$14 / 03 / 2013$ & Aplicação de Pentabiótico Veterinário Reforçado, $12.000 .000 \mathrm{UI} / \mathrm{IM} 30 \mathrm{~mL}$. \\
$16 / 03 / 2013$ & Aplicação de Pentabiótico Veterinário Reforçado, $12.000 .000 \mathrm{UI} / \mathrm{IM} 30 \mathrm{~mL}$. \\
$18 / 03 / 2013$ & Início do fornecimento de Hemolitan, $20 \mathrm{~mL} / \mathrm{VO} /$ dia. \\
20/03/2013 & Aplicação de sulfato de cobre sobre a ferida. Realização de exame diagnóstico raio-X no MPD, não houve
\end{tabular}
presença de alterações.

28/03/2013 Aplicação da $1^{\text {a }}$ dose do IMT Pitium-Vac, SC.

11/04/2013 Realização da cirurgia para remoção do tecido de granulação exuberante. A partir desta data, iniciou-se limpeza diária, duas vezes ao dia, do ferimento com PVPI (iodopovidona), aplicação de pomada de calêndula e administração de megluminato de flunixina por sete dias.

12/04/2013 Aplicação da $2^{\text {a }}$ dose do IMT Pitium-Vac, SC e início do uso iodeto de potássio, 20g VO/dia. Administração de dipirona sódica $14 \mathrm{~mL}$.

13/04/2013 Administração de Pentabiótico Reforçado, 18.000.000 UI, 45 mL.

A $2^{\mathrm{a}}$ dose do IMT foi administrada no músculo peitoral e causou formação de abscesso com secreção purulenta, edema e dor, o equino passou a apresentar claudicação. Administrou-se $6 \mathrm{~mL}$ de fenilbutazona por 3 dias.

26/04/2013 Aplicação da $3^{\text {a }}$ dose do IMT Pitium-Vac, SC.

10/05/2013 Aplicação da $4^{\text {a }}$ dose do IMT Pitium-Vac, SC.

24/05/2013 Aplicação da 5 dose do IMT Pitium-Vac, SC.

07/06/2013 Aplicação da 6 a dose do IMT Pitium-Vac, SC.

08/06/2013 O paciente apresentou alterações no exame clínico, ataxia, claudicação, dor, em decorrência da formação dos abscessos e edema no local de aplicação do IMT, então se administrou fenilbutazona por mais oito dias. No hemograma verificou-se eritropenia e fibrinogênio acima do valor considerado normal para a espécie. Foi realizada fluidoterapia.

09/06/2013 Último dia de administração de iodeto de potássio, pois se pensou que as alterações no exame clínico e hemograma pudessem ser em decorrência de uma suposta intoxicação pela administração do antifúngico.

$12 / 06 / 2013$

Administração de cloridrato de tramadol 5,8 $\mathrm{mL}$, pois o paciente apresentava dor.

13/06/2013 Início da administração de omeprazol 7g, VO.

$21 / 06 / 2013$

Realização de fluidoterapia e aplicação da $7^{\text {a }}$ dose do IMT Pitium-Vac, SC.

$23 / 06 / 2013$

$26 / 07 / 2013$

Realização de fluidoterapia.

Detectada presença do protozoário intra-eritrocitário Babesia equi em exame sanguíneo. Início de tratamento para babesiose com: dipropionato de imidocarb Imizol, fabricante Intervet Schering-Plough), $4,8 \mathrm{~mL}(2,4 \mathrm{~mL}$ pela manhã e $2,4 \mathrm{~mL}$ à tarde) e transfusão de sangue, pois o paciente apresentava eritropenia acentuada

28/06/2013 Administração de dipropionato de imidocarb, 4,8 $\mathrm{mL}(2,4 \mathrm{~mL}$ pela manhã e $2,4 \mathrm{~mL}$ à tarde $)$.

$30 / 06 / 2013$

Administração de dipropionato de imidocarb, $4,8 \mathrm{~mL}$ (2,4mL pela manhã e $2,4 \mathrm{~mL}$ à tarde).

$05 / 07 / 2013$

Aplicação da $8^{\text {a }}$ dose do IMT Pitium-Vac, SC.

19/07/2013 Aplicação da $9^{\text {a }}$ dose do IMT Pitium-Vac, SC.

02/08/2013 Aplicação da $10^{a}$ dose do IMT Pitium-Vac, SC. 


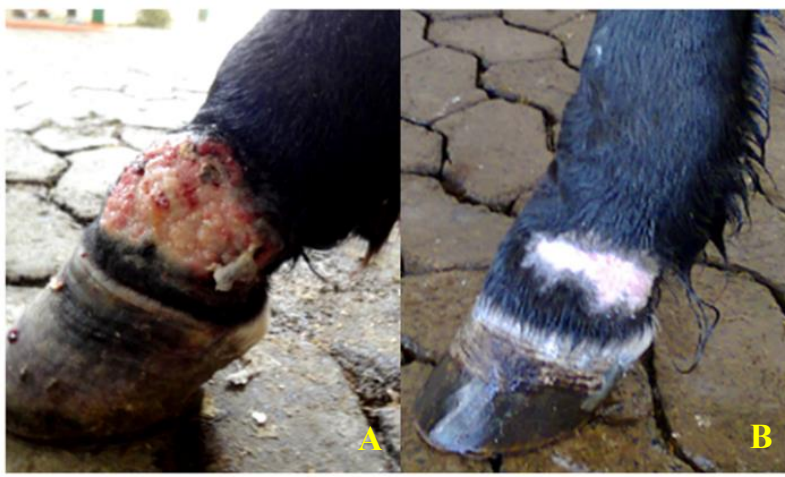

Figura 4. A) Aspecto da ferida antes do tratamento. B). Aspecto da ferida após nove meses de tratamento no $\mathrm{HCV}$.

\section{Resultados e discussão}

$\mathrm{O}$ antimicrobiano utilizado no tratamento do equino reúne em sua composição cinco antibióticos com ação predominantemente bactericida: estreptomicina, benzilpenicilina benzatina, benzilpenicilina procaína, benzilpenicilina potássica e diidroestreptomicina. A antibioticoterapia é um importante aliado do tratamento, pois diminui a ocorrência de infecções secundárias que muitas vezes dificultam o sucesso do tratamento da doença. Mendoza \& Alfaro (1986) descreveram cinco casos crônicos de pitiose em equinos, os quais culminaram em morte por causa da toxemia generalizada, devido à grande contaminação bacteriana nas lesões. Também citam que a imunoterapia apresenta melhores resultados nas fases inicias, e não na fase crônica em que há uma maior destruição de tecidos devido à contaminação por bactérias nas lesões.

$\mathrm{O}$ paciente recebeu um suplemento líquido de administração via oral, que combina em sua formulação vitaminas e oligoelementos que participam direta ou indiretamente do metabolismo celular, principalmente de células sanguíneas e outras de rápida multiplicação. A formulação do suplemento é composta por vitamina $B 1$, vitamina $B 2$, vitamina $B 12$, vitamina $\mathrm{B} 6$, vitamina $\mathrm{K} 3$, pantotenato de cálcio, ácido fólico, ácido nicotínico, cobre, zinco, ferro, cobalto e glicose. Segundo o fabricante, é indicado no manejo nutricional e recuperação de animais que apresentam anemia. De acordo com Santos et al. (2011), a anemia e leucocitose com neutrofilia são achados frequentes em doenças debilitantes crônicas, comuns em processos inflamatórios de etiologia fúngica. A evolução da pitiose é rápida devido à automutilação, com perda significativa de sangue através das feridas levando ao emagrecimento, debilidade orgânica e o animal pode vir a óbito (Bromerschenkel \& Figueiró 2013).

Conforme Barquero \& Higuero (2006), o sulfato de cobre de uso tópico tem ação adstringente, é abrasivo, antisséptico, fungicida, tem ação de secagem, ajudando a combater a infecção. Viana et al. (2014) mencionam o uso de sulfato de cobre como terapia complementar para feridas com tecido de granulação exuberante em equinos.

A dipirona sódica é utilizada para dores musculares, cólicas, processos inflamatórios, febres e após intervenções cirúrgicas. Conforme Melo et al. (2009), os anti-inflamatórios não esteroidais (AINE's), como a fenilbutazona, são considerados a melhor opção para o tratamento das alterações do sistema musculoesquelético, bem como nas afecções gastrintestinais que cursam com endotoxemia.

A administração do iodeto de potássio foi cancelada, pois o equino passou apresentar alterações no exame clínico, e suspeitou-se de intoxicação pelo antifúngico, no entanto as alterações foram em decorrência de reações adversas às aplicações do imunoterápico. Dória et al. (2008) descrevem que a intoxicação por iodo raramente é relatada em equinos. Segundo os autores, cavalos têm uma alta sensitividade ao iodo e relatam um caso, em que o uso excessivo de medicamento à base de iodo, em equino adulto, causou alterações físicas, clínicas, comportamentais e hormonais compatíveis com um quadro de hipotireoidismo.

A administração de omeprazol foi realizada para prevenção de úlceras e gastrites causadas pelo uso de fenilbutazona (Artridine, fabricante Virbac). Segundo Melo et al. (2009), os antiinflamatórios não esteroidais geram diversos efeitos colaterais. As drogas que inibem predominantemente a COX-1 estão associadas ao maior risco de hemorragias, tanto pela inibição na síntese de tromboxano A2, como pela possibilidade de causarem lesões na mucosa gastrointestinal.

O equino diversas vezes apresentou-se apático, com claudicação devido à dor causada pelos abscessos e edema no local de aplicação do IMT. Não se alimentava e não ingeria água adequadamente, apresentando desidratação; portanto foi necessária a realização de fluidoterapia e também administração de cloridrato de tramadol para alívio da dor. Mendoza 
et al. (1996) também relataram complicações associadas à imunoterapia como inchaço, reação inflamatória e infecção bacteriana secundária no local de aplicação das injeções.

A pomada de calêndula tem ação cicatrizante e antisséptica, é indicada no tratamento de lesões superficiais como feridas e ulcerações dérmicas em cães, gatos, equinos e bovinos. Também é indicada no tratamento de queimaduras, escaras e úlceras de decúbito, contusões e pisaduras, cortes acidentais e ou, cirúrgicos. Durante muitos séculos, a calêndula tem sido utilizada para tratar desde lesões cutâneas de tuberculose até mesmo sífilis. Possui uma capacidade para acelerar a cicatrização da pele, alivia dor, inchaço e possui propriedades antimicrobianas (Tilford 2007).

No presente trabalho, optou-se por utilizar no texto o termo "imunoterápico", assim como Gaastra et al. (2010), Tomich et al. (2010) e Santos et al. (2011). Embora alguns autores como Mendoza et al. (1992) e Santúrio \& Ferreiro (2008) tenham empregado a denominação "vacina", o medicamento não possui ação preventiva contra a doença, e é administrado como tratamento de animais diagnosticados com pitiose.

O processo de reparação das feridas causadas pelo oomiceto, assim como foi observado neste caso, geralmente é lento, complicado e, resulta em perdas significativas devido ao considerável número de animais que se encontram impossibilitados de exercer sua função, desenvolvimento de extenso tecido de granulação, claudicação, edemas perilesionais e prognóstico muitas vezes negativo das lesões (Álvarez et al. 2013). A enfermidade requer atenção especial em razão da dificuldade do tratamento e risco que representa para a vida de animais e humanos afetados. Novas perspectivas estão abertas para o estudo da pitiose e seu controle. O aperfeiçoamento da imunoterapia, a produção de uma vacina e não apenas de um imunoterápico, permitirá que os animais desenvolvam uma proteção preventiva contra a doença por determinado período de tempo, a busca por drogas antifúngicas eficientes e, possível utilização de inseticidas que não sejam tóxicos aos mamíferos, são desafios a serem alcançados (Santúrio \& Ferreiro 2008).

Pouco se sabe sobre a virulência do agente e espera-se que o conhecimento sobre a patogenicidade do $P$. insidiosum venha a aumentar quando a sequência completa de nucleotídeos do seu genoma estiver disponível Azevedo et al.
(2012). Em comparação a outros agentes infecciosos, a biologia molecular da patogenicidade do $P$. insidiosum ainda não está bem desenvolvida, assim, continua sendo um agente de grande interesse de estudos e que causa significativas perdas e prejuízos na Medicina Veterinária.

A terapia empregada foi eficiente na diminuição da lesão, o processo cicatricial evoluiu, houve melhora do quadro infeccioso da pele e região subcutânea e ao final do tratamento a ferida encontrava-se quase que totalmente fechada e coberta por pelos. O paciente recebeu alta hospitalar e não apresentou recidiva da lesão até o momento da elaboração desse trabalho.

\section{Conclusão}

A associação do tratamento cirúrgico à administração de antimicóticos, antimicrobianos e imunoterapia aumentou a eficácia do tratamento e se obteve sucesso na cura da doença. Entretanto, observou-se um tratamento prolongado e oneroso, com reações adversas e baixa qualidade de vida do paciente durante o período de tratamento e internação. Assim sendo, a busca por uma terapia adequada para a enfermidade, com menos efeitos colaterais e menor tempo de duração, mostra-se de suma importância para a medicina equina, uma vez que a Pitiose pode provocar grandes prejuízos, debilitando a vida dos pacientes e servindo de porta de entrada para infecções secundárias, as quais podem resultar no óbito do animal.

\section{Referências bibliográficas}

Álvarez J.C., Viloria M.V. \& Ayola S.P. 2013. Pitiose cutânea em equinos: uma revisão. Revista CES Medicina Veterinaria y Zootecnia 8, 58-67.

Azevedo M.I., Botton S.A., Pereira D.I., Robe L.J., Jesus F.P., Mahl C.D., Costa M.M., Alves S.H. \& Santurio J.M. 2012. Phylogenetic relationships of Brazilian isolates of Pythium insidiosum based on ITS rDNA and cytochrome oxidase II gene sequences. Veterinary microbiology 159, 141-148.

Barquero S.C. \& Higuero F.L.P. 2006. Procedimientos normalizados de trabajo: cobre sulfato $1 / 1.000$ solución tópica. Offarm: farmacia y sociedad 25, 125-127.

Bromerschenkel I. \& Figueiró G.M. 2013. Tratamentos do sarcóide equino. Agropecuária Científica no Semiárido 9, 07-10.

Castillo-Jiménez M.C., Baptista-Díaz N., Montero J. \& Pascual Á. 2013. Infección ocular por 
Pythium insidiosum. Enfermedades Infecciosas y Microbiología Clínica 31, 118-119.

Dória R.G.S., Canola P.A., Ribeiro G., Di Filipo P.A., Dias D.P.M. \& Valadão C.A.A. 2008. Hipotireoidismo iatrogênico em eqüino decorrente de excesso de iodo: relato de caso. Arquivo Brasileiro de Medicina Veterinária e Zootecnia 60, 521-524.

Gaastra W., Lipman L.J.A., De Cock A.W.A.M., Exel T.K., Pegge R.B.G., Scheurwater J., Vilela R. \& Mendoza L. 2010. Pythium insidiosum: an overview. Veterinary microbiology 146, 1-16.

Leal A.B.M., Leal A.T., Santurio J.M., Kommers G.D. \& Catto J.B. 2001. Pitiose eqüina no Pantanal brasileiro: aspectos clínicopatológicos de casos típicos e atípicos. Pesquisa Veterinária Brasileira 21, 151-156.

Melo U.P., Fiório R.C., Araújo T.B.S. \& Ferreira C. 2009. Intoxicação por fenilbutazona em equino: relato de caso. Acta Veterinaria Brasilica 3, 111-116.

Mendoza L., Ajello L. \& McGinnis M. 1996. Infections caused by the oomycetous pathogen Pythium insidiosum. Journal de Mycologie Medicale 6, 151-164.

Mendoza L. \& Alfaro A.A. 1986. Equine pythiosis in Costa Rica: report of 39 cases. Mycopathologia 94, 123-129.

Mendoza L., Nicholson V. \& Prescott J.F. 1992. Immunoblot analysis of the humoral immune response to Pythium insidiosum in horses with pythiosis. Journal of clinical microbiology 30, 2980-2983.

Santos C.E.P., Marques L.C., Zanette R.A., Jesus F.P.K. \& Santurio J.M. 2011. Does immunotherapy protect equines from the reinfection by the oomycete Pythium insidiosum? Clinical and Vaccine Immunology 18, 1397-1399.

Santúrio J.M. \& Ferreiro L. 2008. Pitiose: uma abordagem micológica e terapêutica. Editora da UFRGS, Porto Alegre, Rio Grande so Sul.

Tilford G. 2007. Count on calendula: this safe and common herb is famed for its ability to soothe and heal. Whole Dog Journal 10, 1-16.

Tomich T.R., Moraes A.S., Juliano R.S., Abreu U.G.P., Rachel R.C. \& Santurio J.M. 2010. Impacto econômico decorrente do controle da pitiose equina empregando-se o imunoterápico Pitum-Vac. In: Embrapa Pantanal-Artigo em anais de congresso (ALICE), pp. 1-4. $5^{\circ}$ Simpósio Sobre Recursos Naturais e Socioeconômicos do Pantanal. Corumbá MS,1-4.

Viana L.F.S., Wenceslau A.A., Costa S.C.L., Figueiredo M.A.F., Dias F.S.S. \& Ferreira M.L. 2014. Tratamentos complementares para ferida com tecido de granulação exuberante em um equino-Relato de caso. Brazilian Journal of Veterinary Medicine 36, 417-420.

Recebido: 14 outubro, 2018

Aprovado: 10 novembro, 2018.

Publicado: 26 dezembro, 2018.

Licenciamento: Este artigo é publicado na modalidade Acesso Aberto sob a licença Creative Commons Atribuição 4.0 (CC-BY 4.0), a qual permite uso irrestrito, distribuição, reprodução em qualquer meio, desde que o autor e a fonte sejam devidamente creditados. 